\title{
EFFECT OF THE BOTTOM CONFIGURATION ON FILM BOILING HEAT TRANSFER FROM A VERTICAL FINITE-LENGTH CYLINDER
}

\author{
Satoru Momoki \\ Nagasaki University \\ 1-14 Bunkyo-machi, Nagasaki, Nagasaki 852-8521 \\ JAPAN \\ Phone: +81-95-819-2528 \\ momoki@nagasaki-u.ac.jp \\ Toru Shigechi \\ Nagasaki University \\ 1-14 Bunkyo-machi, Nagasaki, Nagasaki 852-8521 \\ JAPAN \\ Phone: +81-95-819-2527 \\ shigechi@nagasaki-u.ac.jp
}

\author{
Takashi Yamada \\ Nagasaki University \\ 1-14 Bunkyo-machi, Nagasaki, Nagasaki 852-8521 \\ JAPAN \\ Phone: +81-95-819-2529 \\ tyamada@nagasaki-u.ac.jp \\ Jambal Odgerel \\ Nagasaki University \\ 1-14 Bunkyo-machi, Nagasaki, Nagasaki 852-8521, \\ JAPAN \\ Phone: +81-95-819-2528 \\ jambal@joule.mech.nagasaki-u.ac.jp
}

Keywords: film boiling, heat transfer, vertical cylinder, conical bottom, hemispherical bottom, flat bottom

\begin{abstract}
In order to clarify the effect of bottom configuration on pool film boiling heat transfer from a vertical finite-length cylinder with a length comparable to the diameter, three kinds of silver cylinder with flat, hemispherical and conical bottoms were tested by quenching in saturated and subcooled water. For saturated water, the wall heat flux averaged over the entire surface of a finite-length cylinder takes a higher value for the cylinder with a conical bottom than those for the other two types as the wall superheat decreases. For highly subcooled bulk water, the average wall heat flux for the cylinder with a flat bottom becomes larger than those for the cylinders with hemispherical and conical bottoms. This is attributed that the cylinder with a flat bottom has quite a thin vapor film at the lower end of the vertical cylinder due to the edge effect. The wall superheat $\left(\Delta T_{\min }\right)$ corresponding to the vapor-film-collapse is constant at about $133 \mathrm{~K}$ for three kinds of test cylinder in saturated bulk water. However, for highly
\end{abstract}

subcooled bulk water $\left(\Delta T_{\text {sub }}=20 \mathrm{~K}\right), \Delta T_{\min }$ with the cylinder with a flat bottom surface is about $60 \mathrm{~K}$ larger than those with hemispherical and conical bottom surfaces.

\section{INTRODUCTION}

Understanding the heat transfer processes during film boiling around three-dimensional high temperature bodies is important in nuclear safety, quenching of metals, manufacturing processes of materials, and so on. Since the study of Bromley(1950), a significant quantity of research has been carried out in regard to film boiling heat transfer (JSME(1989)), and a lot of practical correlations have been proposed for the case of film boiling heat transfer from a single surface such as a vertical surface, a horizontal cylinder, a sphere, an upward facing surface and so on. However, it is still very difficult to predict accurately the film boiling heat transfer around three-dimensional bodies owing to in- 
sufficient knowledge of the heat transfer processes.

Concerning pool film boiling around high temperature bodies, Yamada, et al.(2004, 2007) and Momoki, et al.(2007) have investigated film boiling heat transfer from vertical finite-length cylinders with flat bottom and top surfaces for saturated and subcooled water at atmospheric pressure, analytically and experimentally, and proposed practical correlations of heat transfer. Recently, Yamada, et al.(2010) studied film boiling heat transfer for the case of a finite-length cylinder with a convex-hemispherical bottom and a flat top in regard to the initial heat removal process of emergency core cooling of a nuclear reactor. Through these studies the bottom and top configurations were found to be important in predicting the film boiling heat transfer with a continuous vapor film covering a vertical finite-length cylinder, as the vapor generated under the bottom surface grows thicker during flowing upward along the vertical lateral surface and finally leaves the top surface of a cylinder. Momoki, et al.(2009, 2011) examined the effect of bottom and top configurations on film boiling heat transfer from vertical finite-length cylinders with a hemispherical surface as the bottom and top surfaces by comparing with a cylinder with flat bottom and top surfaces. In the film boiling around a vertical finite-length cylinder, the bottom configuration plays an important role from the point of heat transfer rate, as the vapor generated under the bottom surface flows upward along the vertical lateral surface and the vapor film covering a vertical finite-length cylinder controls the convective heat transfer.

In this study, the effect of a bottom configuration on film boiling heat transfer from the entire surface of a vertical finite-length cylinder during quenching in saturated and subcooled water at atmospheric pressure was examined using four cylinders including a finite-length cylinder with a conical bottom. Further, the measured values for four types of cylinder were reported for the wall superheat at the lower limit of film boiling defined as the minimum cooling rate.

\section{NOMENCLATURE}

$c \quad$ specific heat of the cylinder

$D \quad$ cylinder diameter

$h$ heat transfer coefficient averaged over the entire surface

$h_{\mathrm{i}} \quad$ heat transfer coefficient averaged on the $i$ surface

$L \quad$ lateral vertical length of a cylinder

$Q \quad$ total heat transfer rate from the cylinder

$Q_{\mathrm{i}} \quad$ heat transfer rate on the $i$ surface

$q \quad$ wall heat flux averaged over the entire surface

$S \quad$ total surface area of a cylinder

$S_{\mathrm{i}} \quad$ surface area on the $i$ surface

$T \quad$ cylinder temperature

$T_{\mathrm{i}} \quad$ initial temperature of the cylinder

$T_{\infty} \quad$ bulk liquid temperature

$\Delta T_{\text {sat }} \quad$ wall superheat

$\Delta T_{\text {sub }}$ liquid subcooling

$\Delta T_{\min }$ wall superheat at the lower limit of film boiling

$V \quad$ cylinder volume

$\rho \quad$ density

$\tau \quad$ time

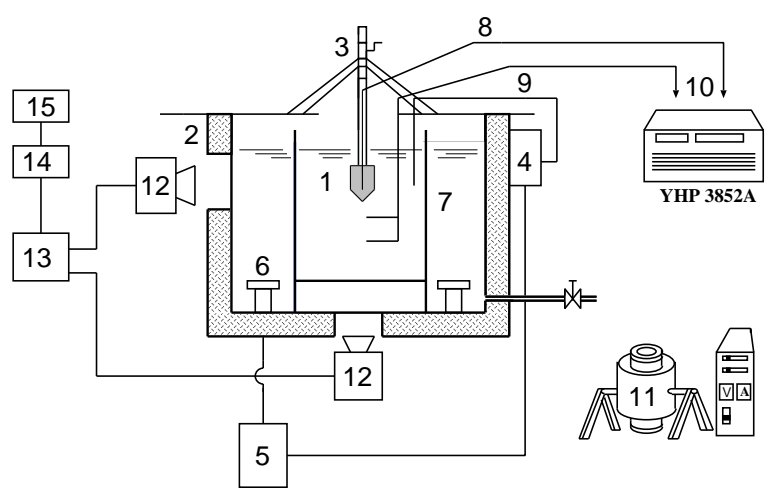

1. Test cylinder 2. Boiling bath 3. Lifting device

4. Temperature controller 5. Power controller

6. Heater 7. Glass box 8. K-type thermocouple

9. K-type thermocouple 10. Data acquisition/control unit 11. Electric furnace 12. Video camera

13. Video cassette recorder 14. Digital AV mixer

15. Video monitor

Fig. 1 Schematic of experimental apparatus

Subscripts

b downward facing surface of the cylinder (bottom)

$\mathrm{t}$ upward facing surface of the cylinder(top)

$\mathrm{v} \quad$ vertical lateral surface of the cylinder

\section{EXPERIMENTS}

\subsection{Experimental Apparatus, Test section and Procedure}

Figure 1 shows the experimental apparatus made up of a boiling bath, cylinder heating furnace, lifting device, temperature measurement system and observational systems for the boiling phenomena. The boiling bath with an inside dimension of $450 \times 450 \times 750 \mathrm{~mm}$ is made of stainless steel and glass windows are placed on the lateral and bottom sides for viewing the boiling process. The test liquid is water at atmospheric pressure and heated up indirectly by two $2 \mathrm{~kW}$ immersion type electric heaters placed outside the glass box with a dimension of $300 \times 300 \times 600 \mathrm{~mm}$ to prevent bubbles generated on the electric heaters from disturbing the bulk liquid around the test cylinder. The water temperature is kept at a prescribed value by a temperature controller.

Figure 2 shows cross-sectional views of four types of test cylinders made of $99.99 \%$ pure silver. The lower ends of the test cylinders for Type B and Type $\mathrm{C}$ are formed by machining convex-hemispherical and convex-conical, respectively. The diameter of test cylinders, $D$, is $32 \mathrm{~mm}$ and the length, $L$, is between 32 and $48 \mathrm{~mm}$, that is, the aspect ratios, $L / D$, are ranging from 1.0 to 1.5 .

The configurations of the bottom for the test cylinders are classified into three kinds: (1)Type A-1 and Type A-2 with a flat bottom, (2)Type B with a convex-hemispherical bottom and (3)Type $\mathrm{C}$ with a convex-conical bottom, where the top surfaces of test cylinders are all flat. Two test cylinders with a flat bottom (Type A-1 and Type A-2) are prepared to examine the effect of cylinder length on film boiling heat transfer. The cylinder with Type B has a convex- 


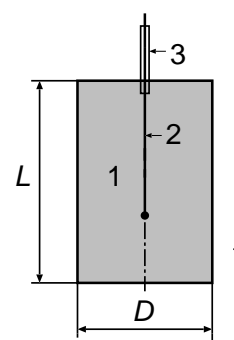

Type A-1
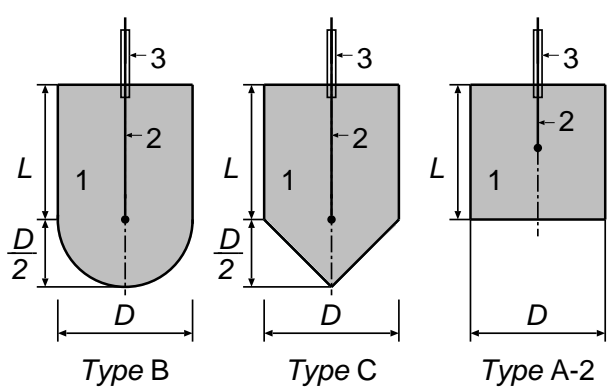

1. test cylinder 2. K-type thermocouple $(\phi 1 \mathrm{~mm})$

3. supporting stainless tube $(\phi 4 \mathrm{~m} \times \phi 3 \mathrm{~mm})$

\begin{tabular}{|c|c|c|c|c|c|}
\hline \multirow{2}{*}{ Type } & \multicolumn{2}{|c|}{ cylinder size } & $S$ & $V$ & $V / S$ \\
\cline { 2 - 6 } & $D[\mathrm{~mm}]$ & $L[\mathrm{~mm}]$ & {$\left[\mathrm{cm}^{2}\right]$} & {$\left[\mathrm{cm}^{3}\right]$} & {$[\mathrm{mm}]$} \\
\hline A-1 & 32 & 48 & 64.3 & 38.6 & 6.00 \\
\hline B & 32 & 32 & 56.3 & 34.3 & 6.09 \\
\hline C & 32 & 32 & 51.6 & 30.0 & 5.82 \\
\hline A-2 & 32 & 32 & 48.3 & 25.7 & 5.33 \\
\hline
\end{tabular}

Fig. 2 Test cylinders

Table 1 Surface area ratio for each surface of the test cylinder

\begin{tabular}{|c|c|c|c|c|c|}
\hline \multirow{2}{*}{ surface } & \multirow{2}{*}{ ratio } & \multicolumn{4}{|c|}{ Type } \\
\cline { 3 - 6 } & & $\mathrm{A}-1$ & $\mathrm{~B}$ & $\mathrm{C}$ & $\mathrm{A}-2$ \\
\hline top & $S_{\mathrm{t}} / S$ & 0.1250 & 0.1429 & 0.1559 & 0.1667 \\
\hline $\begin{array}{c}\text { vertical } \\
\text { lateral }\end{array}$ & $S_{\mathrm{v}} / S$ & 0.750 & 0.5714 & 0.6236 & 0.6666 \\
\hline bottom & $S_{\mathrm{b}} / S$ & 0.1250 & 0.2857 & 0.2205 & 0.1667 \\
\hline
\end{tabular}

hemispherical bottom with a blunt tip, while the cylinder with Type $\mathrm{C}$ is a sharp tip due to a convex-conical bottom. The main dimensions and the thermocouple location are also illustrated in Fig.2. The entire surface of a finite-length cylinder is divided into three parts with bottom, vertical lateral and top surfaces to elucidate the heat transfer mechanism for film boiling around a finite-length cylinder (Yamada, et al.(2004, 2007, 2010), Momoki, et al.(2007, 2009)). Each surface area ratio is defined as $S_{\mathrm{i}} / S$, where $S_{\mathrm{i}}$ is each surface area and $S$ is the total surface area. Table 1 shows each surface area ratio, $S_{\mathrm{i}} / S$. Comparing the vertical lateral surface area ratio $\left(S_{\mathrm{V}} / S\right)$ between Type A-1 and A-2 with flat bottom and top surfaces, the former has a nearly $13 \%$ larger ratio than the latter. A sheathed K-type thermocouple with an outside diameter of $1 \mathrm{~mm}$ is located on the cylinder axis through a stainless steel support tube to measure the transient temperature of the test cylinder. The temperature history is recorded using a YHP 3852A data acquisition/control unit with a sampling time of 0.25 seconds.

Prior to each test, the surface of the test cylinder was mirror-finished by buff polishing and cleaned with alcohol to ensure the initial condition of the surface remained constant. After heated to about $600{ }^{\circ} \mathrm{C}$ in an electric furnace, the test cylinder was submerged with a depth of $100 \mathrm{~mm}$ into the quiescent water at atmospheric pressure using a lifting device and subsequently cooled down. The temperature of bulk water was varied in the range from $80^{\circ} \mathrm{C}$ to $100^{\circ} \mathrm{C}$. The quenching phenomena around a cylinder were observed by viewing using high speed video camera and still photograph.

\subsection{Measurements of Temperature and Wall Heat flux}

The inner part of the test cylinder is assumed to be cooled uniformly and its temperature is calculated as a lumped parameter system as the test cylinder is made of silver which inherently has high thermal conductivity. Thus, the wall heat flux averaged on the entire surface, $q$, is given as

$$
q=-\rho c(V / S)(d T / d \tau)
$$

where $c, S, V$ and $\rho$ are, respectively, specific heat, total heating surface, volume of the test cylinder and density. $T$ and $\tau$ denote temperature of the cylinder and elapsed time from the beginning of the cooling process, respectively. The lower limit of the film boiling is defined in this study as the point where the cooling rate, $-d T / d \tau$, gives a minimum value and the corresponding wall superheat is referred to as $\Delta T_{\min }$. The assumption for a lumped parameter system is confirmed by the numerical calculation results of the two-dimensional unsteady heat conduction in the cylinder and a small Biot number which was estimated to be less than 0.04. The maximum error of measurement for the wall heat flux calculated from Eq. (1) was estimated to be less than $15 \%$. In addition, the maximum heat loss from the stainless steel tube support was estimated to be less than $2 \%$ under the condition of subcooled water.

\section{RESULTS AND DISCUSSION}

\subsection{Visual Observation}

The vapor film around four types of vertical finite-length cylinder was observed using both still and video cameras. Figures 3 (a) and (b) show the observed film boiling for saturated water $\left(\Delta T_{\text {sub }}=0 \mathrm{~K}\right)$ and subcooled water $\left(\Delta T_{\text {sub }}=20 \mathrm{~K}\right)$, respectively, at $\Delta T_{\text {sat }} \approx 350 \mathrm{~K}$.

In saturated film boiling, the test cylinders are entirely covered by a thick vapor film with wavy vapor-liquid interface. The vapor film for Type A-1 and Type A-2 with a flat bottom surface is always thicker than those for Type B and Type $\mathrm{C}$ with hemispherical and conical surfaces. This is due to the difference of driving force for the vapor flow under the bottom surface. Under the downward-facing horizontal circular surface a stable vapor film is formed and the radial flow in the vapor film from the cylinder center to the edge is driven by the hydrostatic pressure gradient due to both the vaporliquid density difference and the gradient in vapor film thickness in the flow direction (Shigechi, et al.(1989), Yamada, et al.(1998), Momoki, et al.(1995)). However, for the cylinders with hemispherical and conical surfaces, the upward vapor flows along the bottom surface are driven by the vapor-liquid density difference, i.e, the two-phase buoyant force and during flowing upward along the bottom and vertical lateral surface the vapor film becomes thick with a wavy vapor-liquid interface. In subcooled film boiling, the vapor film around the 


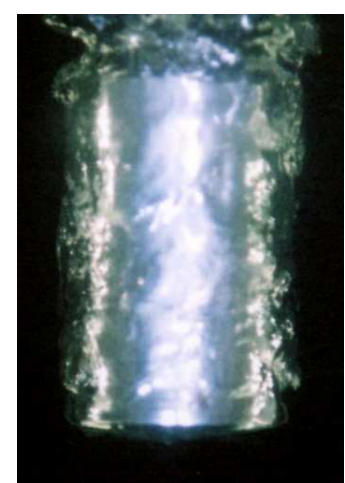

Type A-1

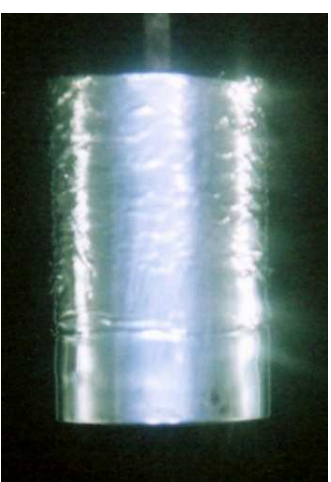

Type A-1

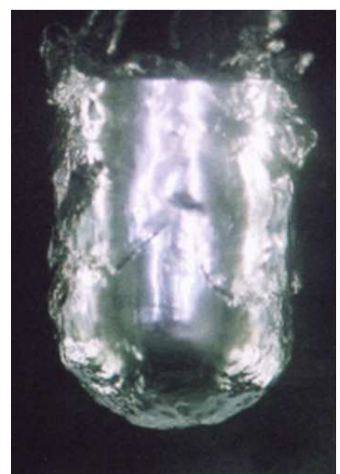

Type B

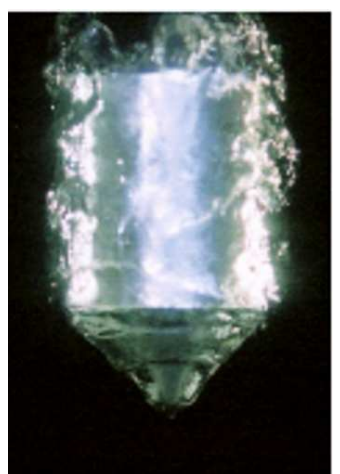

Type $\mathrm{C}$

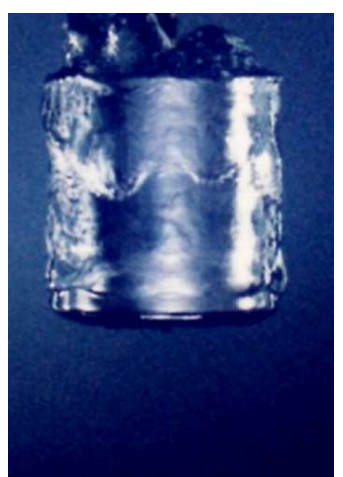

Type A-2

(a)saturated water ( $\left.\Delta T_{\text {sub }}=0 \mathrm{~K}, \Delta T_{\text {sat }} \approx 350 \mathrm{~K}\right)$

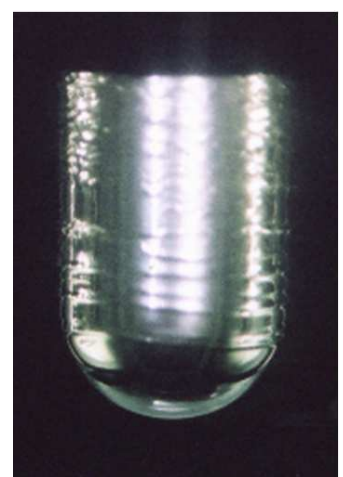

Type B

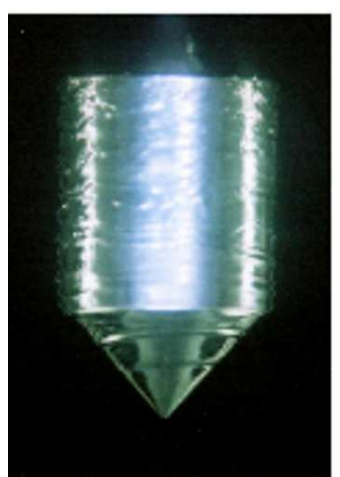

Type C

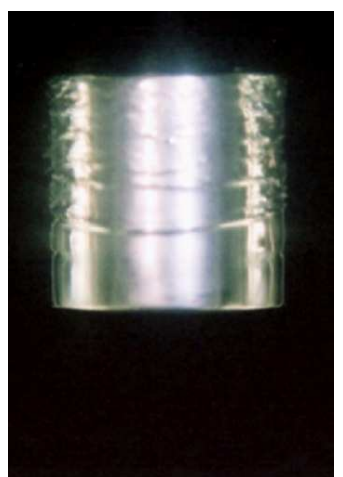

Type A-2

(b)subcooled water ( $\left.\Delta T_{\text {sub }}=20 \mathrm{~K}, \Delta T_{\text {sat }} \approx 350 \mathrm{~K}\right)$

Fig. 3 Photographs of vapor film formed around a vertical finite-length cylinder

cylinder becomes thinner with an increasing liquid subcooling and the vapor-liquid interface remains nearly smooth, as shown in Fig. 3(b). Some ring-like wrinkles on the vaporliquid interface are formed in constant vertical distance with a constant rising velocity.

It was observed that the vapor film collapse started at the lower(bottom) edge of the cylinder for Type A-1 and Type A-2 (Yamada, et al.(2004, 2007), and at the upper edge for Type B(Yamada, et al.(2010). As the cylinder with Type C has three edges, i.e., the upper and the lower edges of the vertical lateral surface, and the tip of the bottom cone, which are liable to make vapor film unstable, vapor film collapse seems to occur at the lower edge in saturated water but at the upper(top) edge or the tip of the cone in subcooled liquid (Yamada, et al.(2011). The vapor film collapse spreaded out rapidly on the entire surface for both saturated and subcooled film boiling.

\subsection{Cooling Characteristics}

\subsubsection{Cooling curve}

Cooling curves measured for four types of cylinders are shown in Fig. 4 in terms of dimensionless temperature $\left(T-T_{\infty}\right) /\left(T_{\mathrm{i}}-T_{\infty}\right)$ and cooling time, $\tau$, where $T_{\mathrm{i}}$ and $T_{\infty}$ are, respectively, the initial temperature in the measurement and the bulk liquid temperature. The solid circle on each cool- ing curve in the figure shows the lower limit of film boiling defined as the point where the cooling rate, $-d T / d \tau$, gives a minimum value. It is seen from the figure that the cooling curves for the test cylinders differ significantly depending on both the bottom configurations of the cylinders and the magnitude of liquid subcooling. Elapsed time of cooling for the temperature of the cylinder to approach to that of the bulk water is shorter with an increasing liquid subcooling.

\subsubsection{Cooling rate in the film boiling region}

The cooling rate of a cylinder, $-d T / d \tau$, is, as shown by Eq.(1), proportional to the wall heat flux, $q$, and the inverse of $V / S . q$ depends on heat transfer from the entire surface of the cylinder and the magnitude of $V / S$ is different depending on the bottom configuration, as shown in Fig. 2. The cooling rate of a cylinder, $-d T / d \tau$, in the film boiling region is shown in Fig. 5 using cooling time, $\tau$, as the abscissa. It is seen from Fig. 5 that the cooling rates for the test cylinders differ significantly dependent on the bottom configurations of the test cylinders and that the cooling rate in the film boiling region and the point of lower limit of film boiling becomes higher with an increasing liquid subcooling. The cylinder with Type $\mathrm{C}$ has a larger cooling rate than the other three cylinders for a saturated water $\left(\Delta T_{\mathrm{sub}}=0 \mathrm{~K}\right)$, while the cylinder with Type A2 has a larger cooling rate than the other three cylinders for a highly subcooled water $\left(\Delta T_{\text {sub }}=20 \mathrm{~K}\right)$. At the lower limit 
of film boiling, the cooling rate, $-d T / d \tau$, is higher with an increasing liquid subcooling. Elapsed time of cooling in the film boiling region is shorter with an increasing liquid subcooling.

\subsubsection{Wall superheat at the lower limit of film boiling}

The wall superheat at the lower limit of film boiling is shown as a solid circle in Figs. 4 and 5. Figure 6 shows the relationship between the wall superheat at the lower limit of film boiling, $\Delta T_{\min }$, and the liquid subcooling, $\Delta T_{\text {sub. For sat- }}$ urated water, $\Delta T_{\min }$ is constant at about $133 \mathrm{~K}$ for four types

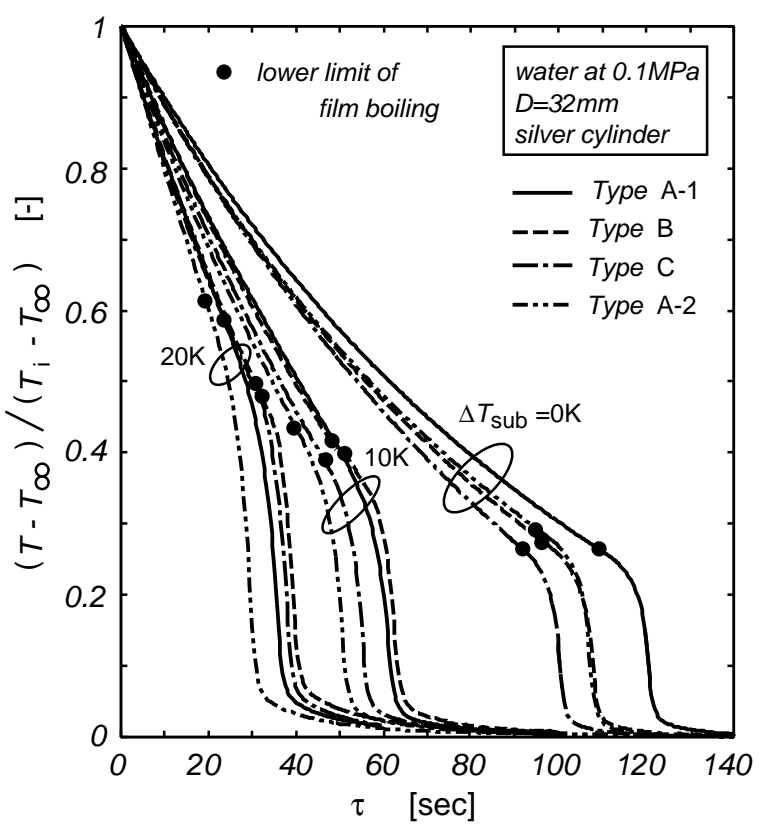

Fig. 4 Cooling curve

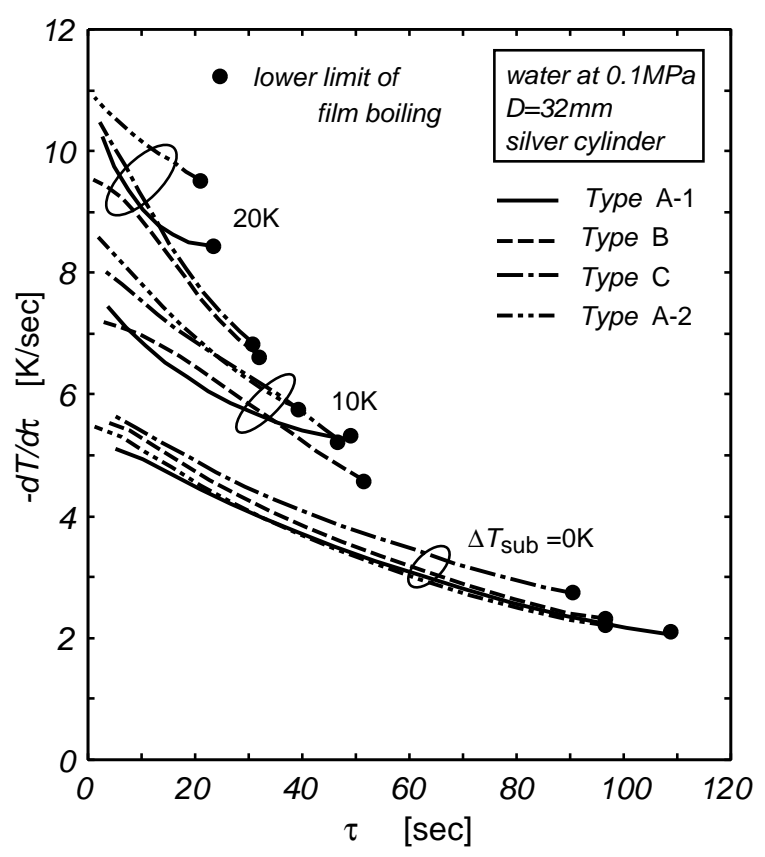

Fig. 5 Cooling rate curve in the film boiling region of cylinder irrespective of the bottom configurations. However, for subcooled water, $\Delta T_{\min }$ depends strongly on $\Delta T_{\text {sub }}$ and increases linearly as $\Delta T_{\text {sub }}$ increases. For the cylinders with a flat bottom surface (Type A-1 and Type A-2), $\Delta T_{\min }$ is nearly $60 \mathrm{~K}$ higher than that with hemispherical and conical bottom surfaces (Type B and Type $\mathrm{C}$ ) at a liquid subcooling of $20 \mathrm{~K}$. Two cylinders with a flat bottom(Type A-1 and Type A-2) show similar dependence of $\Delta T_{\min }$ on $\Delta T_{\text {sub }} \Delta T_{\min }$ for the cylinder with a conical bottom (Type C) is slightly larger than that with a hemispherical bottom (Type B) in saturated and subcooled liquid. The vapor film around the cylinder with a conical bottom seems to be liable to become more unstable than that with a hemispherical bottom.

\subsection{Film Boiling Characteristics}

\subsubsection{Boiling curve in the film boiling region}

Figure 7 shows the boiling curves calculated by Eq.(1) using the cooling curves given in Fig. 4, taking the liquid subcooling, $\Delta T_{\text {sub }}$, as a parameter. It is seen from Fig. 7 that the film boiling curves are significantly affected by the bottom configurations and that the wall heat flux averaged over the entire surface of a cylinder, $q$, has a larger value with an increasing liquid subcooling and the point of the lower limit of film boiling shifts to the region of higher wall superheat with an increasing liquid subcooling.

Though the diameters for the cylinders of Type A-1, Type $\mathrm{B}$ and Type $\mathrm{C}$ are equal to $32 \mathrm{~mm}$, the volume and entire surface area of the cylinders vary due to different bottom configurations, as shown in Fig. 2. The vertical lateral length, $L$, of Type A-1 is $48 \mathrm{~mm}$ and $16 \mathrm{~mm}$ longer than that of the two cylinders of Type B and Type C. Another cylinder with a flat bottom, Type A-2, which has a vertical lateral length equal to the diameter $(32 \mathrm{~mm})$, is prepared to examine the effect of the difference in vertical lateral length between Type A-1 and Type A-2 on boiling curve. It is understood from Fig. 7 that the effect of vertical lateral length of the cylinder on heat transfer is not so large concerning the cylinders of Type A-1

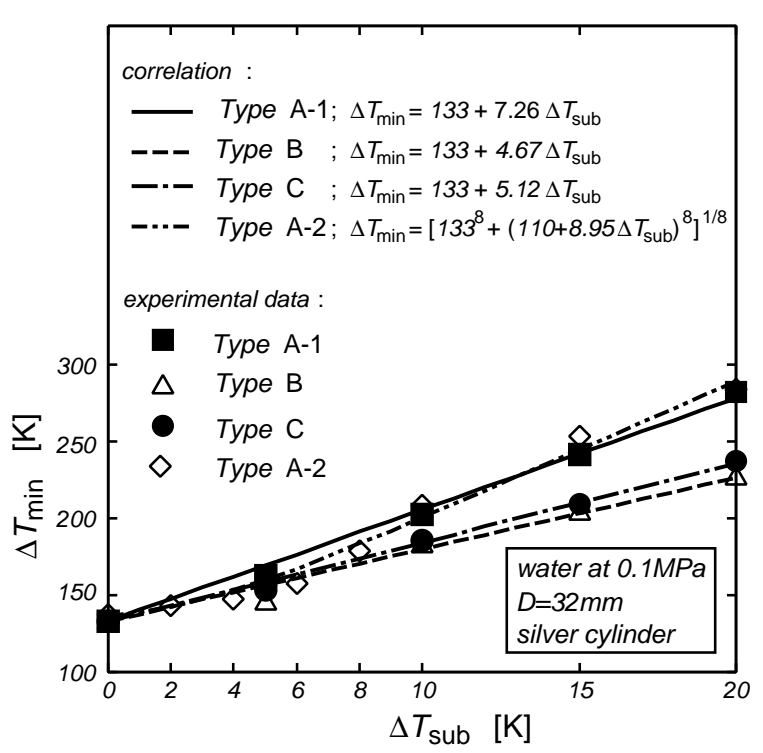

Fig. 6 Wall superheat at the lower limit of film boiling 


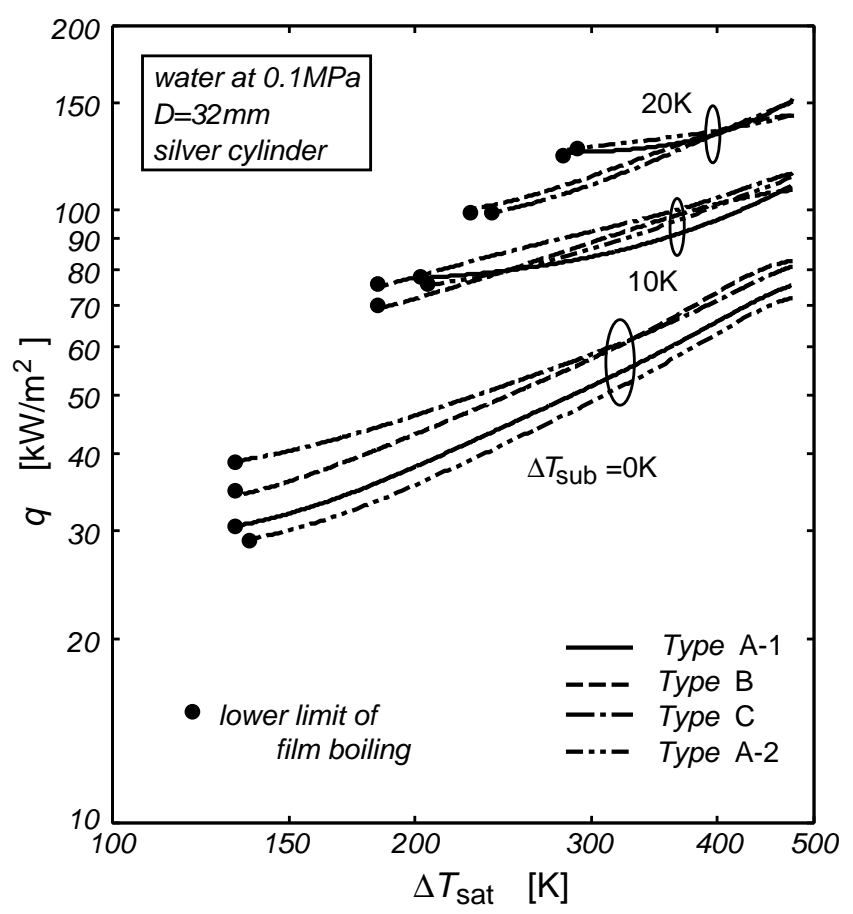

Fig. 7 Boiling curve in the film boiling region

and Type A-2 and that the average wall heat flux, $q$, for Type A-1 is a few percents higher than that for Type A-2 in saturated boiling and vice versa in highly subcooled condition at a fixed wall superheat.

For saturated water $\left(\Delta T_{\text {sub }}=0 \mathrm{~K}\right)$, it is seen from Fig. 7 that the values of the wall heat flux, $q$, vary in order of Type A-2 < Type A- $1<$ Type B < Type $\mathrm{C}$ at a lower wall superheat and the maximum $q$ at Type $\mathrm{C}$ is about $35 \%$ higher than the minimum $q$ at Type A-2 at $\Delta T_{\text {sat }}=150 \mathrm{~K}$. At a liquid subcooling of $10 \mathrm{~K}$, four cylinders show almost equal heat transfer rate. At a liquid subcooling of $20 \mathrm{~K}$, the magnitude order of $q$ is changed as Type $\mathrm{C}<$ Type $\mathrm{B}<$ Type A- $1<$ Type A- 2 in the region of lower wall superheat. The magnitudes of $q$ for Type A-1 and Type A-2 become larger than those for Type B and Type $\mathrm{C}$ as the wall superheat decreases and/or the liquid subcooling increases.

\subsubsection{Heat transfer coefficient in the film boiling region}

The average heat transfer coefficient defined as $h=$ $q / \Delta T_{\text {sat }}$ is shown in Fig. 8. The magnitude of $h$ varies in the range from $150 \mathrm{~W} /\left(\mathrm{m}^{2} \mathrm{~K}\right)$ to $450 \mathrm{~W} /\left(\mathrm{m}^{2} \mathrm{~K}\right)$ for $133 \mathrm{~K}<\Delta T_{\text {sat }}$ $<475 \mathrm{~K}$ and $0 \mathrm{~K}<\Delta T_{\text {sub }}<20 \mathrm{~K}$. The dependence of $h$ on wall superheat is stronger with an increasing liquid subcooling and particularly the dependences for the cylinders with a flat bottom (Type A-1 and Type A-2) are steeper in the lower wall superheat region. Momoki, et al.(2011) discussed the relationship between the magnitudes of the average heat transfer coefficient in the film boiling region and the bottom and top configurations of finite-length cylinders with Type A-1, Type A-2 and Type B. In this paper, the magnitudes of $h$ are discussed focusing on the difference of bottom configuration including a new cylinder with Type $\mathrm{C}$.
For saturated and subcooled film boiling around a vertical finite-length cylinder, the authors (Yamada, et al.(2004, 2007, 2010), Momoki, et al. (2007, 2009)) have proposed a heat transfer model composed of three regions with bottom, vertical lateral and top surfaces. The heat transfer rate from the entire surface of a vertical finite-length cylinder, $Q$, is defined as the sum of the heat transfer rate from the downwardfacing bottom surface, $Q_{\mathrm{b}}$, the vertical lateral surface, $Q_{\mathrm{v}}$, and the upward facing top surface, $Q_{\mathrm{t}}$. Thus, the following relation is obtained.

$$
\begin{aligned}
Q & =Q_{\mathrm{b}}+Q_{\mathrm{v}}+Q_{\mathrm{t}} \\
q & =Q / S=h \Delta T_{\mathrm{sat}} \\
h & =q / \Delta T_{\mathrm{sat}}=\left[h_{\mathrm{b}}\left(S_{\mathrm{b}} / S\right)+h_{\mathrm{v}}\left(S_{\mathrm{v}} / S\right)+h_{\mathrm{t}}\left(S_{\mathrm{t}} / S\right)\right]
\end{aligned}
$$

where $S_{\mathrm{b}}, S_{\mathrm{v}}$ and $S_{\mathrm{t}}$ are the areas for the bottom, vertical lateral and top surfaces, respectively, and $S$ is the total surface area. i.e., $S=S_{\mathrm{b}}+S_{\mathrm{v}}+S_{\mathrm{t}}$, and $h_{\mathrm{b}}, h_{\mathrm{v}}$ and $h_{\mathrm{t}}$ are the average heat transfer coefficients for the bottom, vertical lateral and top surfaces, respectively. The magnitude of $S_{\mathrm{i}} / S(i=\mathrm{b}, \mathrm{v}, \mathrm{t})$ was shown in Table 1 for four types of test cylinder.

For saturated water $\left(\Delta T_{\text {sub }}=0 \mathrm{~K}\right)$, the magnitudes of the average heat transfer coefficient on the bottom surface, $h_{\mathrm{b}}$, for the cylinders of Type B and Type $C$ were predicted using analytical solutions with a smooth vapor-liquid interface by Bromley model for Type B (Frederking and Clark(1963)) and Type C (Toyoda, et al.(2011)). From the prediction, the magnitude of $h_{\mathrm{b}}$ for Type $\mathrm{C}$ with a convex conical bottom is slightly larger than that for Type B with a convex hemispherical bottom due to the sharp bottom tip where the vapor film thickness approaches to zero, while the surface area ratio of the bottom surface, $S_{\mathrm{b}} / S$, for Type $\mathrm{C}$ is about $23 \%$ smaller than that for Type B as shown in Table 1. The magnitudes of $h_{\mathrm{v}}$ and $h_{\mathrm{t}}$ for the cylinder of Type B were given by Momoki, et al.(2011). The driving forces of upward vapor flow along the bottom surfaces of the cylinders with Type $B$ and Type $C$ are the same, i.e., a two-phase buoyant force. The vapor film at the lower edge of the vertical lateral surface for Type $\mathrm{C}$ is thinner than that for Type B. Therefore, the magnitude of $h_{\mathrm{V}}$ for the cylinder of Type $\mathrm{C}$ is considered to be larger than that of Type B. The magnitudes of $h_{\mathrm{t}}$ on the top surface for Type B and Type $\mathrm{C}$ are presumed to be nearly equal. From these considerations combined to the surface area ratios given in Table 1 through Eq.(4), the magnitude of $h$ for Type C seems to be comparable to that of Type B. However, as seen in Fig.8, the magnitude of $h$ for Type $C$ is higher than those for the other three cylinders in saturated water. The reason seems to be that the wave action on the vapor-liquid interface for Type $\mathrm{C}$, as shown in Fig.3 (a), enhanced the film boiling heat transfer.

For a highly subcooled water $\left(\Delta T_{\text {sub }}=20 \mathrm{~K}\right)$, the cylinders of Type A-1 and A-2 have high average heat transfer coefficients as shown in Fig. 8 in the region of lower wall superheat. The reason is considered as follows. The average heat transfer coefficients on the vertical lateral surface, $h_{\mathrm{v}}$, for Type $\mathrm{B}$ and Type $\mathrm{C}$ become relatively small as the vapor film thickness at the lower edge of the vertical lateral surface is thick due to the upward vapor flow from the bottom surface. While, the cylinders of Type A-1 and A-2 have very large values of $h_{\mathrm{v}}$ in the region of lower wall superheat. This is at- 
tributed that the vapor film generated under the flat bottom is thick at the center, becomes thinner toward the edge and flows upward around the right-angled sharp edge with a fast velocity and that the subcooled liquid near the vapor-liquid interface is disturbed due to the vapor flow around the rightangled edge. High values of $h_{\mathrm{v}}$ obtained in such cases are appeared in the experimental studies reported by Vijaykumar and Dhir(1992a, 1992b) for a vertical surface with a thick leading edge vapor layer under strongly subcooled condition.

\section{CONCLUTIONS}

Film boiling heat transfer from four types of finite-length silver cylinder with flat, hemispherical and conical bottoms were examined by quenching experiments in saturated and subcooled water at atmospheric pressure. The following results were drawn from the experiments.

(a) In the boiling curves for saturated water, the average wall heat flux takes a higher value for the cylinder with a conical bottom and a lower value for the cylinder with a flat bottom than that for the cylinder with a hemispherical bottom. The difference in average wall heat flux between four types of test cylinder becomes larger with a decreasing wall superheat due to the difference in driving force of vapor flow.

(b)For highly subcooled bulk water, the average wall heat flux for the case with a flat bottom becomes larger than those for the cases with hemispherical and conical bottoms. This seems to be attributed that the cylinder with a flat bottom has a sharp leading edge at the lower end of the vertical cylinder and there the vapor film becomes much thinner and the subcooled liquid near the vapor-liquid interface is disturbed due to the vapor flow around the right-angled sharp edge.

(c)The minimum wall superheat $\left(\Delta T_{\min }\right)$ corresponding to the vapor-film-collapse is constant at nearly $133 \mathrm{~K}$ for four

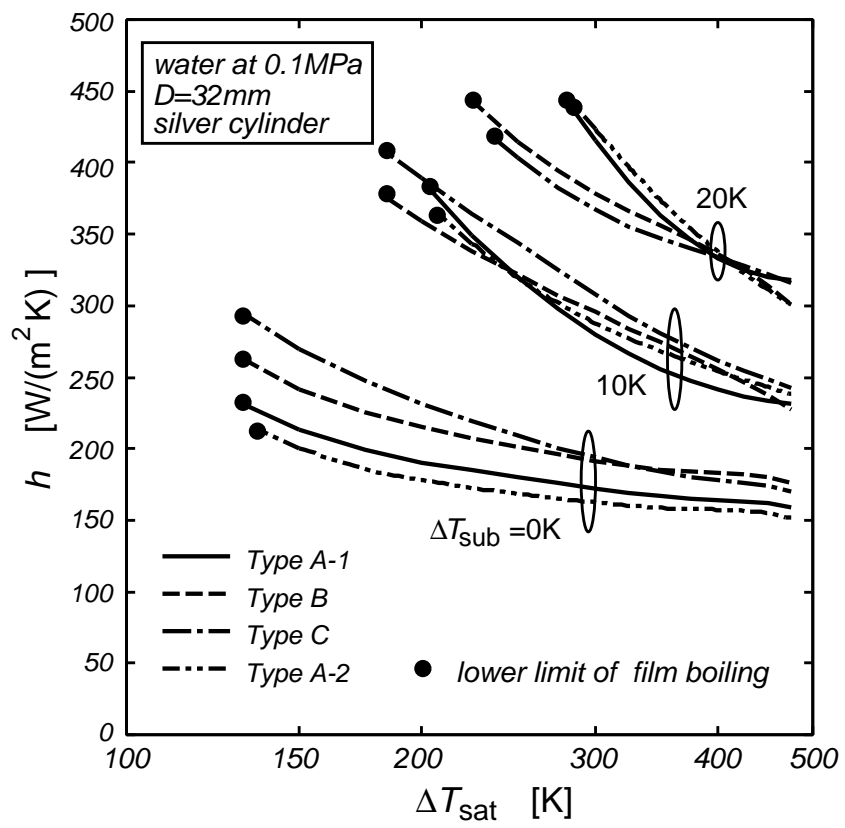

Fig. 8 Average heat transfer coefficient in the film boiling region kinds of test cylinder in saturated bulk water. However, for highly subcooled bulk water $\left(\Delta T_{\text {sub }}=20 \mathrm{~K}\right), \Delta T_{\min }$ with the case of a flat bottom surface is nearly $60 \mathrm{~K}$ larger than those with the cases of hemispherical and conical bottom surfaces.

\section{REFERENCES}

Bromley, L. A., 1950, "Heat Transfer in Stable Film Boiling", Chem. Eng. Progress, Vol.46, pp.221-227.

Frederking, T. H. K. and Clark, J. K. 1963, "Natural Convection Film Boiling on a Sphere", Advances in Cryogenic Engineering, Vol.8, pp.501-506.

Momoki, S., et al., 1995, "Effect of Liquid Subcooling on the Film Boiling Heat Transfer from a Finite-size Horizontal Plate Facing Downward", Proceedings of the 4th ASME/JSME Thermal Engineering Conference, Vol.2, pp. 265-272

Momoki, S., et al., 2007, "Film Boiling around a Vertical Cylinder with Top and Bottom Horizontal Surfaces", Proceedings of the 2007 ASME-JSME Thermal Engineering Summer Heat Transfer Conference, HT2007-32733, CDROM.

Momoki, S., et al., 2009, "Experiments and Analysis on Film Boiling Heat Transfer around a Finite-length Vertical Cylinder with a Convex Surface Facing Downward", Journal of Power and Energy Systems, Vol.3, No.1, pp.182-193.

Momoki, S., et al., 2011, "Effect of the Bottom and Top Configurations on Pool Film Boiling around a Vertical Finitelength Cylinder", Proceedings of the ASME/JSME 2011 8th Thermal Engineering Joint Conference, AJTEC2011-44122, CD-ROM.

Shigechi, T., et al., 1989, "Film Boiling Heat Transfer from a Horizontal Circular Plate Facing Downward", JSME International Journal, Series II, Vol.32, No.4, pp.646-651.

Toyoda, K., et al., 2011, “An Analysis of Saturated Pool Film Boiling Heat Transfer around a Vertical Finite-length Cylinder with a Convex Conical Bottom", Reports of the Faculty Engineering, Nagasaki University, Vol.41, No.76. (to be published, in Japanese).

Vijaykumar, R. and Dhir, V. K. 1992a, “An Experimental Study of Subcooled Film Boiling on a Vertical Surface Hydrodynamic Aspects", J. Heat Transfer, Vol.114, pp.161168.

Vijaykumar, R. and Dhir, V. K. 1992b, “An Experimental Study of Subcooled Film Boiling on a Vertical Surface Thermal Aspects", J. Heat Transfer, Vol.114, pp.169-178.

Yamada, T., et al., 1998, "Effect of Liquid Subcooling on Film Boiling Heat Transfer from Finite-size Horizontal Surfaces Facing Downward", Trans. Jpn. Soc. Mech. Eng. Ser. B, Vol.64, No.628, pp.4159-4165. (in Japanese)

Yamada, T., et al., 2004, "Film Boiling Heat Transfer around a Vertical Finite-length Cylinder", Trans. Jpn. Soc. Mech. Eng. Ser. B, Vol.70, No.695, pp.1762-1768. (in Japanese)

Yamada, T., et al., 2007, "Subcooled Film Boiling Heat Transfer around a Vertical Finite-length Cylinder", Trans. Jpn. Soc. Mech. Eng. Ser. B, Vol.73, No.732, pp.1715-1722. (in Japanese)

Yamada, T., et al., 2010, "Film Boiling Heat Transfer around a Vertical Finite-length Cylinder with a Con- 
vex Hemispherical Bottom", Heat Transfer-Asian Research, Vol.39, No.3, pp.166-177.

Yamada, T., et al., 2011, "Experiments on Film Boiling Heat Transfer around a Vertical Finite-length Cylinder with a Convex Conical Bottom", Reports of the Faculty Engineering, Nagasaki University, Vol.41, No.76. (to be published, in Japanese).

The Japan Society of Mechanical Engineers, 1989, "Boiling Heat Transfer and Cooling", pp.128-156 (in Japanese). 